\title{
CONCOMITANT DOSING WITH ANTAGONISTS IMPROVED TACROLIMUS (FK506)-INDUCED NEPHROTOXICITY IN RATS
}

\author{
Toshiyuki Fujii, Takashi Mitamura, Atsushi Yamada, Shiro Fujihira, Kaname \\ Ohara, and Yasuhiro Mine \\ Toxicology Research Laboratories, Fujisawa Pharmaceutical Co., Ltd.
}

\begin{abstract}
FK506-induced nephrotoxicity has been reported to occur by arteriolar constriction of the renal cortex, which is induced through the production of such vasoactive factors as thromboxane $A_{2}\left(T X A_{2}\right)$, renin, etc. In the present study, we investigated whether FK506-induced nephrotoxicity is improved by concomitant antagonists for TX $\mathrm{A}_{2}$, angiotensin II, endothelin, adenosine, adrenergic $\alpha_{2}$ receptor, platelet activating factor, and calcium channel, and found that some showed a potentiality of being antidotes to FK506-induced nephrotoxicity. A calcium antagonist showed the best improving effects and was followed by a $T X A_{2}$ dual inhibitor and an angiotensin II antagonist. An $\alpha_{2}$ blocked showed a slight improvement, but endothelin, adenosine, and platelet activating factor (PAF) antagonists had no effects on the nephrotoxicity. The results suggested that FK506induced nephrotoxicity occurs by constriction of the renal artery, and that various vasoactive factors are involved. In the present study, FK506 and antagonists for vasoconstrictive factors were dosed to rats and the parameters of nephrotoxicity were examined. In this kind of study, antidotes need not only improve the toxicity of the main drug; they must not diminish its pharmacological action. Accordingly, both toxic and pharmacological parameters must be investigated in a study aimed at finding an antidote to side effects of medicine. Thus, in the present paper we put forth our opinions about estimation of concomitant dosing. (J Toxicol Pathol 9: 277 $\sim 284$, 1996)
\end{abstract}

Key words : Tacrolimus (FK506), Acute nephrotoxicity, Vasoconstriction, Concomitant dosing, Rat

\section{Introduction}

Ideally, drugs should have no side effects, or have a wide safety margin if they do have side effects. However, drugs, not always safe, are clinically used in life threatening diseases such as cancer or organ transplantation. Immunosuppressants belong to this kind of drug. Although immunosuppressants are used on the basis of risk and benefit, it is desirable that their risk is reduced as much as possible.

Tacrolimus (FK506), an immunosuppressant ${ }^{1}$ developed by Fujisawa Pharmaceutical Co., Ltd., has been used clinically in the field of organ transplantation ${ }^{2}$, and has been found to be an effective suppressor of transplant rejection. In contrast to its good efficacy, however, some side effects

\section{藤井登志之 三田村孝 山田 篤 藤平司郎}

小原 要 峯 靖弘

Accepted for publication: June 24, 1996

Mailing address: Toshiyuki Fujii, Toxicology Research Laboratories, Fujisawa Pharmaceutical Co., Ltd. Kashima 2-1-6, Yodogawa, Osaka, 532, Japan. have occurred, one of them being impairment of renal function $^{3-5}$. We have already reported the profile of FK506-induced nephrotoxicity in rats ${ }^{6}$. The present study was performed to search for antidotes for this toxicity.

\section{Materials and Methods}

\section{Animals}

Male spontaneous hypertensive rats (SHR) (Charles River Japan, Inc.) with blood pressure of $180-220 \mathrm{mmHg}$, aged 11-13 weeks and weighing 270$330 \mathrm{~g}$ were used for the study. During the acclimation and study periods the animals were allowed free access to standard solid food (CE-2, Clea Japan, Inc.) and tap water.

\section{Experimental design}

\section{Experiment 1}

FK506 formulation for intramuscular injection 
(Fujisawa Pharmaceutical Co. Ltd.) was diluted with physiological saline and injected intramuscularly to the animals (7/group) in a daily dose of 1,2 , or $4 \mathrm{mg}$ / $\mathrm{kg} /$ day for 14 days. The control animals were given the placebo formulation corresponding to $4 \mathrm{mg} / \mathrm{kg}$ of FK506 in the same way.

After the last dosing, each animal was housed in a metabolism cage and the 24-hour urine was collected for the examinatiton of urine volume, $\mathrm{N}$ acetyl- $\beta$-D-glucosamidase (NAG) activity, and creatinine content. NAG activity and creatinine content were assayed by a colormetric method using an NAG test kit (Shionogi \& Co., Ltd.) and CREEN KAINOS (KAINOS Laboratories, Inc.), respectively. Additionally, urinary thromboxane $B_{2}$ (TX $B_{2}$ ) and 6-keto-prostaglandin $F_{1 \alpha}$ (6-keto-PGF $\left.\right|_{1 \alpha}$ ), which are stable metabolites of thromboxane $A_{2}$ and prostacyclin, respectively, were measured by radio immunoassay (Amersham Japan). After urine collection, the animals were anesthetized with ether, and blood was collected from the artery. Serum creatinine, blood urea nitrogen (BUN), and plasma renin activity were analyzed with an autoanalyzer (Type 7150, Hitachi, Ltd.), and by radio immunoassay (Dinabot Co., Ltd.). Creatinine clearance was calculated from urinary creatinine and serum creatinine. Blood concentrations of FK506 were measured by ELISA with a monoclonal anti-FK 506 antibody? After blood collection, the animals were bled to death, and the kidney was excised and examined histopathologically.

\section{Experiment 2}

FK506 was given intramuscularly to the animals in a daily dose of $4 \mathrm{mg} / \mathrm{kg}$ for 2 weeks in combination with the test compounds which were various kinds of antagonists for vasoconstrictive factors. The test compounds were given twice a day immediately before and 4 hours after dosing with FK506. The doses were set on the basis of pharmacological and toxic doses, and dose routes are shown in the following Table 1.

After dosing for 2 weeks, urine and blood creatinine was measured and creatinine clearance was calculated, and the kidneys of the animals were examined histopathologically in the same way as in

Table 1. Test Compounds, Dose Route, and Dosage

\begin{tabular}{llrrr}
\multicolumn{1}{c}{ Test agent } & Route & \multicolumn{4}{c}{$\begin{array}{c}\text { Dose } \\
\text { (mg/kg/day) }\end{array}$} \\
\hline TX A $_{2}$ dual inhibitor & p.o. & 200 & 400 \\
Angiotensin II antagonist & s.c. & 1 & 10 & \\
Endothelin antagonist & s.c. & 10 & & \\
Adenosine antagonist & p.o. & 10 & & \\
$\alpha_{2}$ blocker & i.p. & 1 & 2 & \\
PAF antagonist & i.v. & 2 & 5 & \\
Calcium antagonist & s.c. & 0.2 & 1 & 2 \\
\hline
\end{tabular}

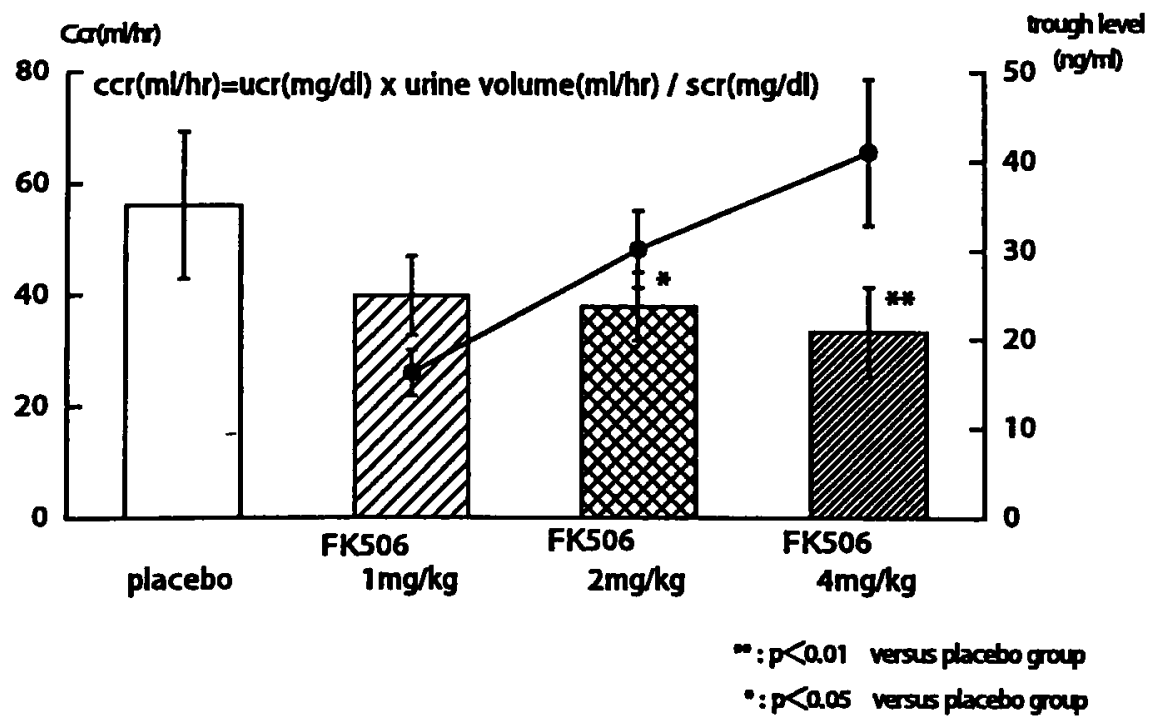

Fig. 1. Creatinine clearance and trough levels of FK506 in SHR dosed i.m. for 2 weeks. 
experiment 1 .

\section{Statistical Analysis}

The results were expressed as the mean \pm S.D. Statistical analysis between the treated and control groups or placebo group was made by Student's $t$ test.

\section{Results}

Experiment 1. FK506-induced nephrotoxicity in rats

There were no abnormal changes in any groups in urine volume or NAG activity in urinalysis, whereas serum creatinine and BUN increased dosedependently in each group. Creatinine clearance decreased dose-dependently with statistical significance between the 2 or $4 \mathrm{mg} / \mathrm{kg}$ group and placebo group (Fig. 1). The blood trough levels of

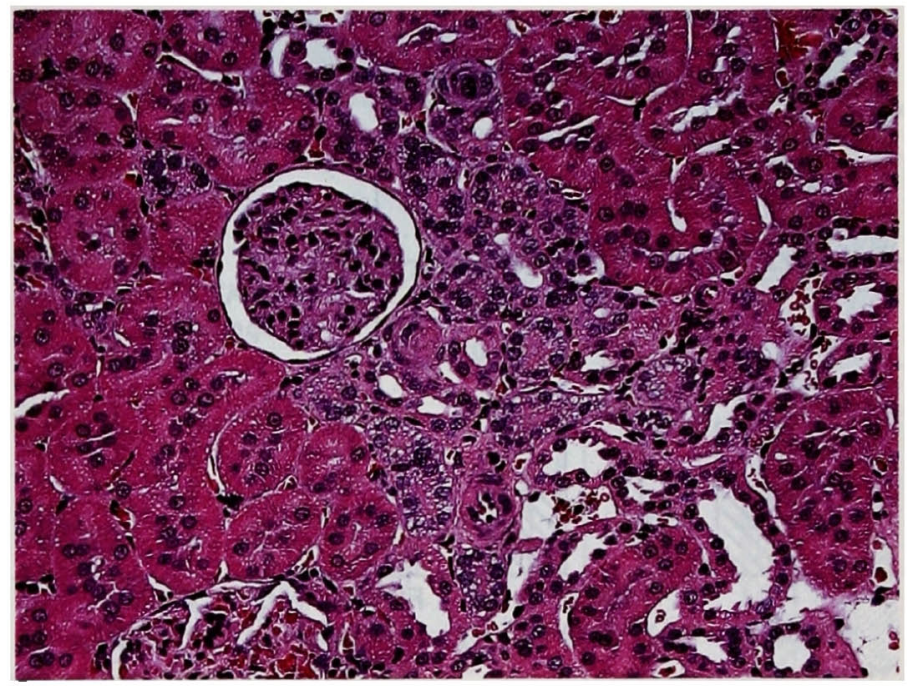

Fig. 2. Narrowing of the arterioles and basophilic cortical tubules in the kidney of FK506 in SHR dosed i.m. with $4 \mathrm{mg} / \mathrm{kg} /$ day for 2 weeks. $\mathrm{HE} \times 100$

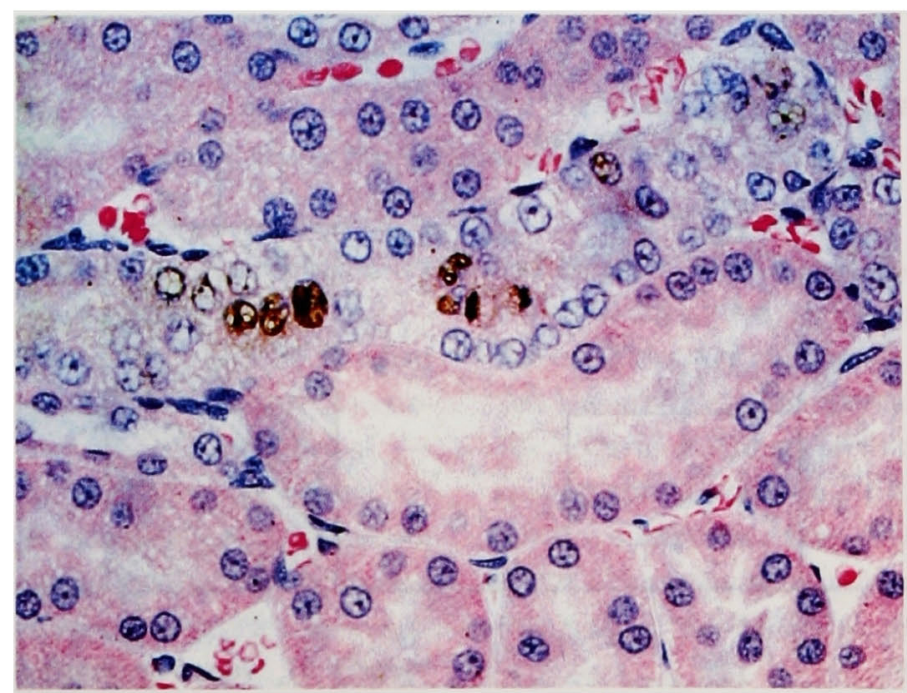

Fig. 3. PCNA immunostaining of basophilic cortical tubules in the kidney. $\times 200$ 
FK506 in the 1,2 , and $4 \mathrm{mg} / \mathrm{kg}$ groups were $16.2 \pm$ 2.6, $30.1 \pm 4.3$, and $41.0 \pm 8.2 \mathrm{ng} / \mathrm{ml}$, respectively (Fig. 1). From the above results, the nephrotoxicity of FK506 in rats was considered to be induced at the through levels of $30 \mathrm{ng} / \mathrm{ml}$ or more. On the other hand, in histopathology of the kidney, luminal narrowing of the cortical arterioles and basophilic tubules around the arterioles were observed dose-dependently (Fig. 2, HE). There was a mixture of cells showing apoptosis and proliferating cell nuclear antigen (PCNA) immuno-staining positive cells (Fig. 3) at the basophilic tubular area.

Thromboxane $\mathrm{A}_{2}$ ( $\mathrm{TX} \mathrm{A}_{2}$ ) has the strongest constricting action of the vessel among eicosanoids. Urinary thromboxane $\mathrm{B}_{2}$, a stable metabolite of TX $A_{2}$, increased significantly in the 2 and $4 \mathrm{mg} / \mathrm{kg}$ groups compared with that in the placebo group. On the other hand, 6-keto-PGF $\mathrm{Ia}_{\mathrm{a}}$, a stable metabolite from prostacyclin which has the strongest dilating action of the vessel among eicosanoids, decreased in the FK506 treated groups (Fig. 4). In addition, plasma renin activity was measured only in the $4 \mathrm{mg}$ / $\mathrm{kg}$ group and was higher than that in the control (Fig. 5). Expression of renin m-RNA was noted in the juxtaglomerular cells of the kidney of rats treated with FK506 (Fig. 6). These results suggest that $\mathrm{TXA}_{2}$

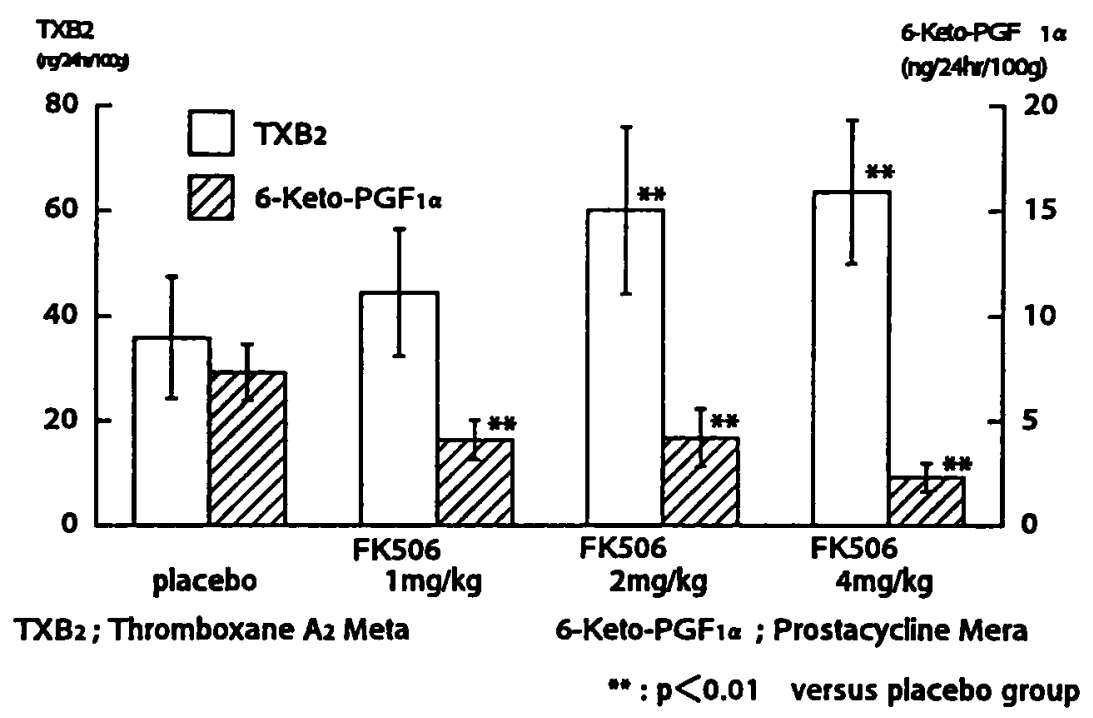

Fig. 4. Urinary eicosanoids ( $\mathrm{TXB}_{2}$ and 6-Kete-PGF ${ }_{1 \alpha}$ ) in SHR dosed i.m. with FK506 for 2 weeks.

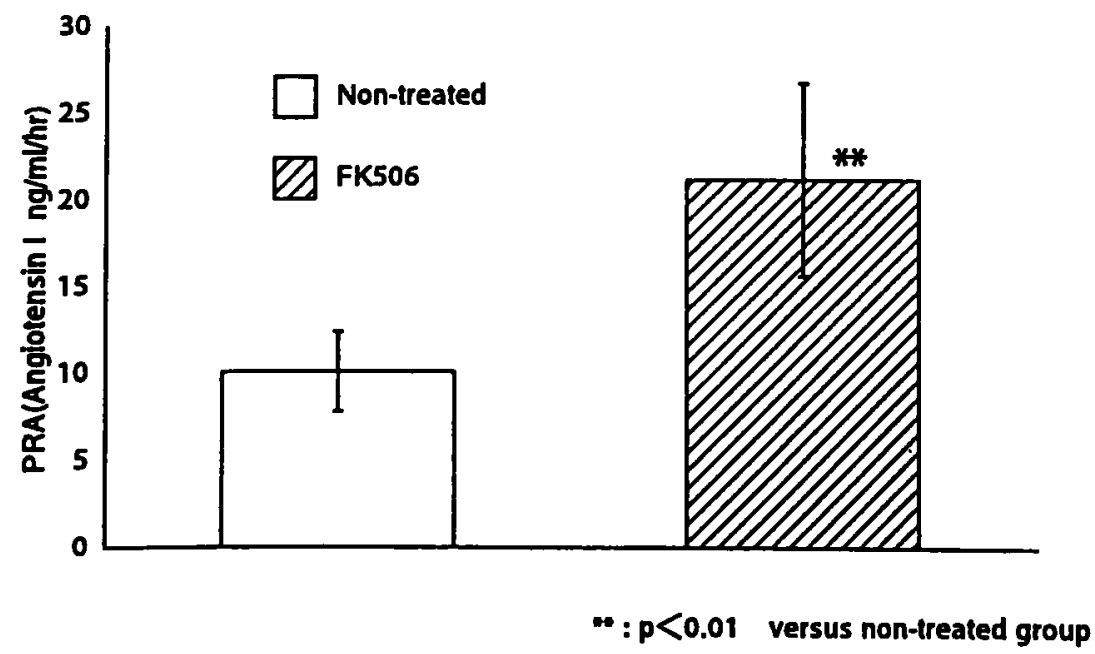

Fig. 5. Plasma renin activity in SHR dosed i.m. with $4 \mathrm{mg} / \mathrm{kg}$ FK506 for 2 weeks. 


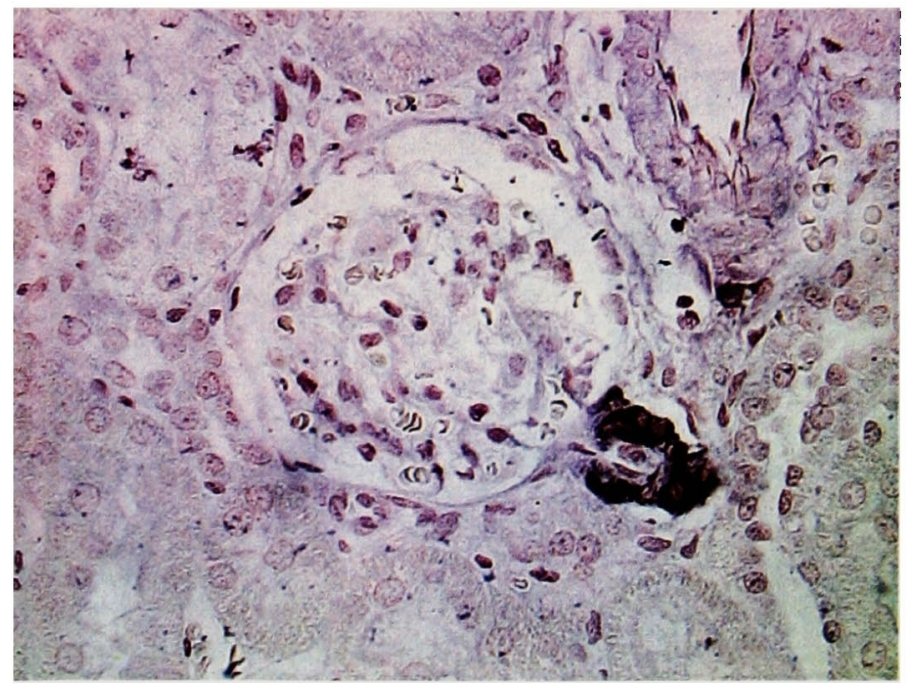

Fig. 6. Renin mRNA in situ hybridization method of the juxtaglomerular apparatus in the kidney. $\times 200$

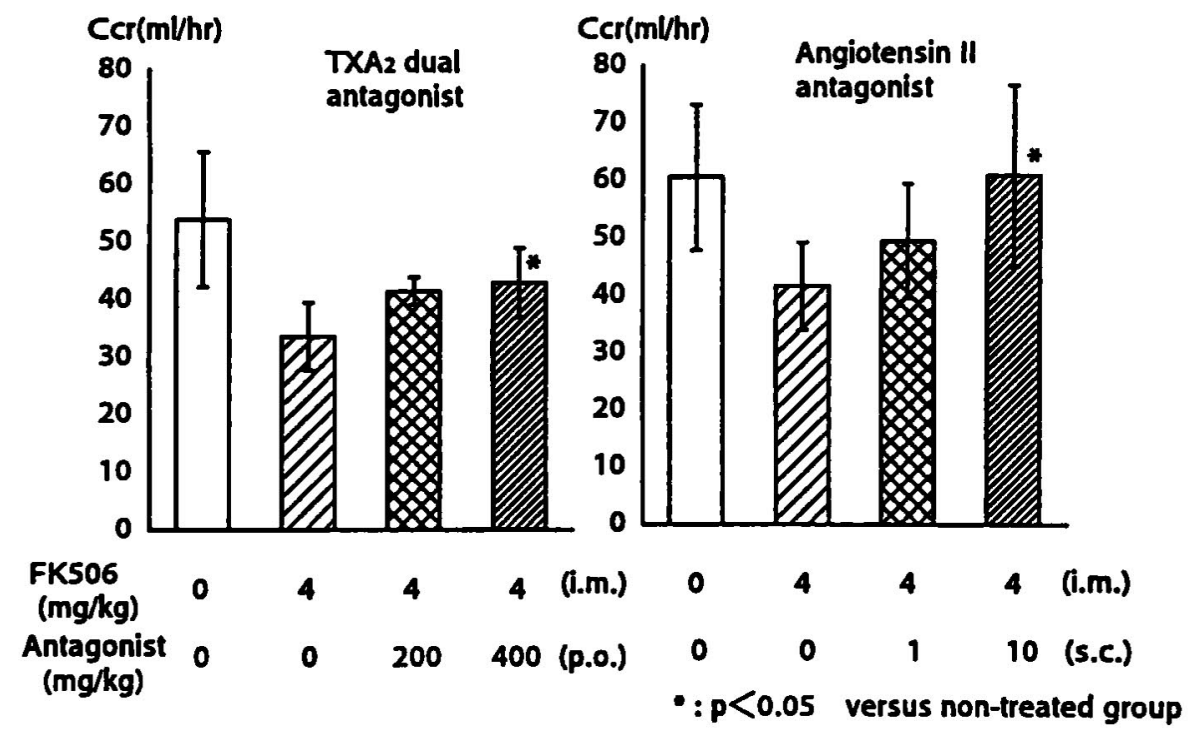

Fig. 7. Effect of vasocontracting factor antagonists on FK506 nephrotoxicity.

and renin would participate in the induction of nephrotoxicity in rats treated with FK506.

Experiment 2. Alleviation of renal impairment by concomitant dosing with antagonists for vasoconstrictive factors

A thromboxane $A_{2}$ dual inhibitor and an angiotensin II antagonist improved the decrease in creatinine clearance induced by FK506 (Fig. 7), but endothelin and adenosine antagonists did not have an improving effect (not shown). An $\alpha_{2}$ blocker showed a slight improvement, but PAF antagonist had no effect (Fig. 8). Finally, a calcium antagonist improved creatinine clearance values (Fig. 9) and decreased blood creatinine and BUN to normal levels, and histopathologically the kidney was normal (Fig. 10). The blood trough levels of FK 506 at the time of concomitant dosing with $0.2,1$, and $2 \mathrm{mg} / \mathrm{kg}$ of calcium antagonist were $37.0 \pm 5.6,45.6 \pm 7.4$, and $42.4 \pm 9.3 \mathrm{ng} / \mathrm{ml}$, respectively, compared with $42.7 \pm$ $5.4 \mathrm{ng} / \mathrm{ml}$ in the FK506 alone dosing (Fig. 9); The calcium antagonist did not affect the blood levels of FK506. 


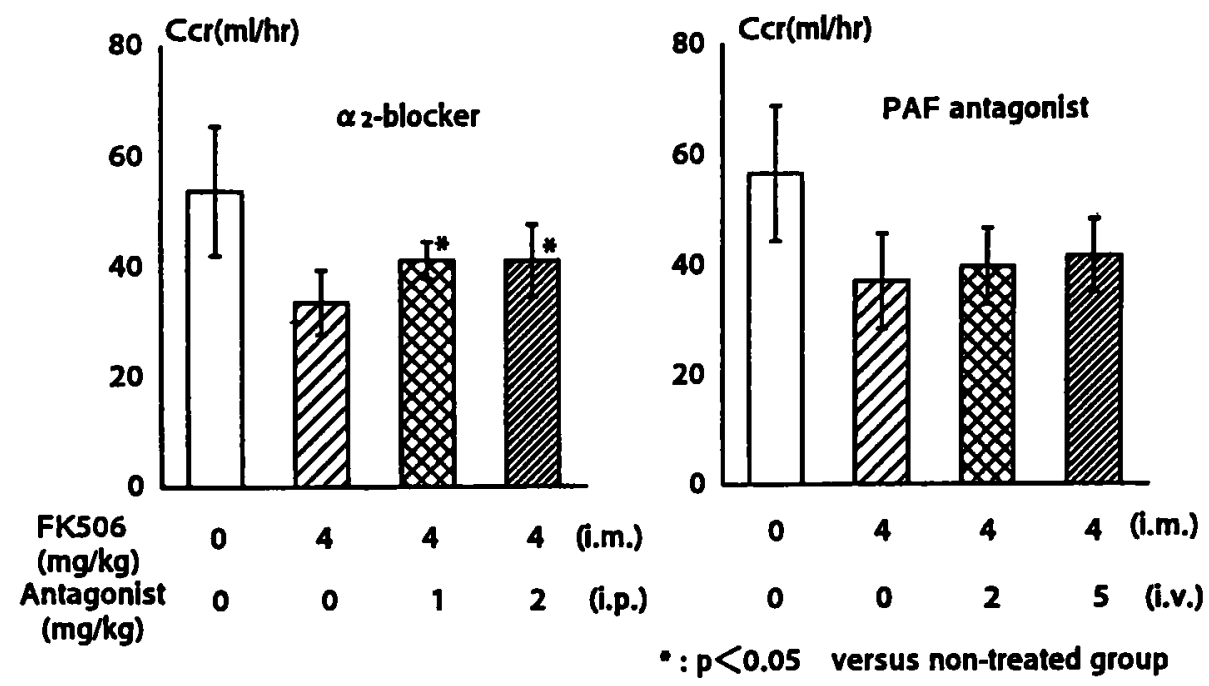

Fig. 8. Effect of vasocontracting factor antagonist on FK506 nephrotoxicity.

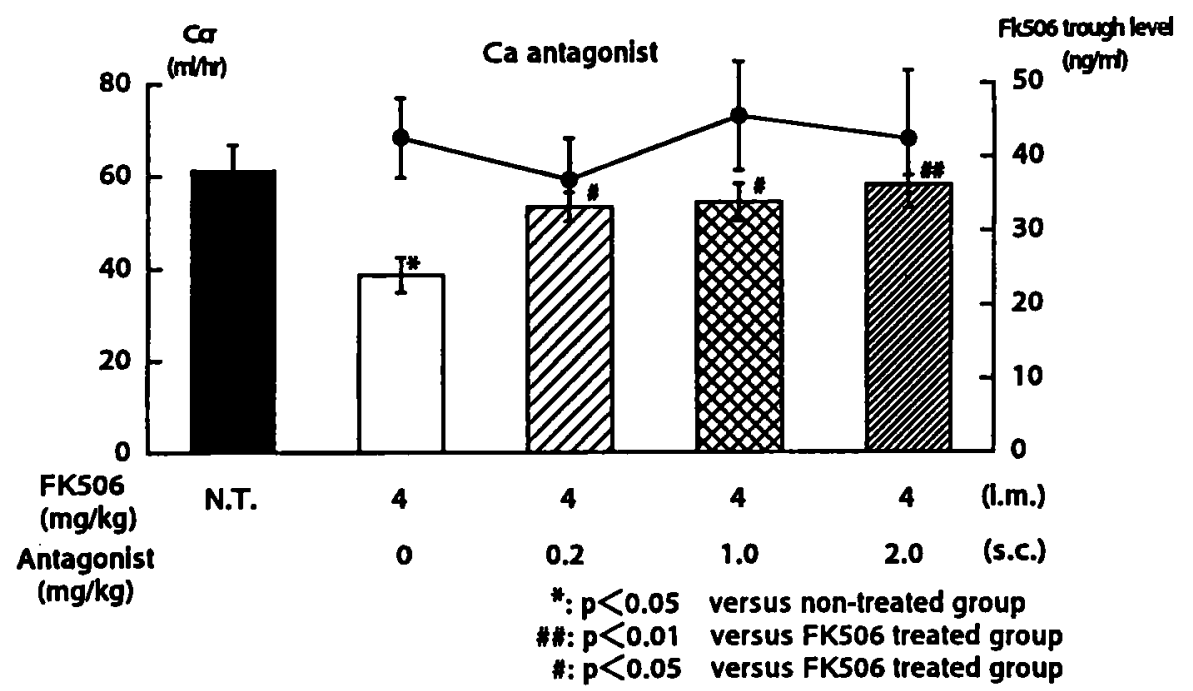

Fig. 9. Effect of vasocontracting factor antagonist on FK506 nephrotoxicity.

\section{Discussion}

The acute nephrotoxicity by FK506 was characterized by increases in blood creatinine and BUN and a decrease in creatinine clearance, and its histopathological changes were luminal narrowing of the arterioles in the renal cortex and basophilic tubules around the area. A luminal narrowing of the arterioles was also reported by Kyo et al. using Wistar rats $^{8}$. All these changes quickly returned to normal when FK506 was withdrawn ${ }^{6}$. From the results, FK506-induced nephrotoxicity was considered to be mediated by the constriction of renal arterioles followed by decreases in blood flow and glomerular filtration in the kidney. By urinary analysis, an increase of $\mathrm{TX} \mathrm{B}_{2}$ and a decrease of 6-keto-PGF suggest that FK506 induced nephrotoxicity is associated with the constriction of renal arterioles. Additionally, a vesoconstrictive mechanism via the reninangiotensin system was also considered to participate since blood renin activity increased and renin mRNA appeared in the kidney.

Among the test compounds used as antidotes, the effect of TX $A_{2}$ dual antagonist and angiotensin 


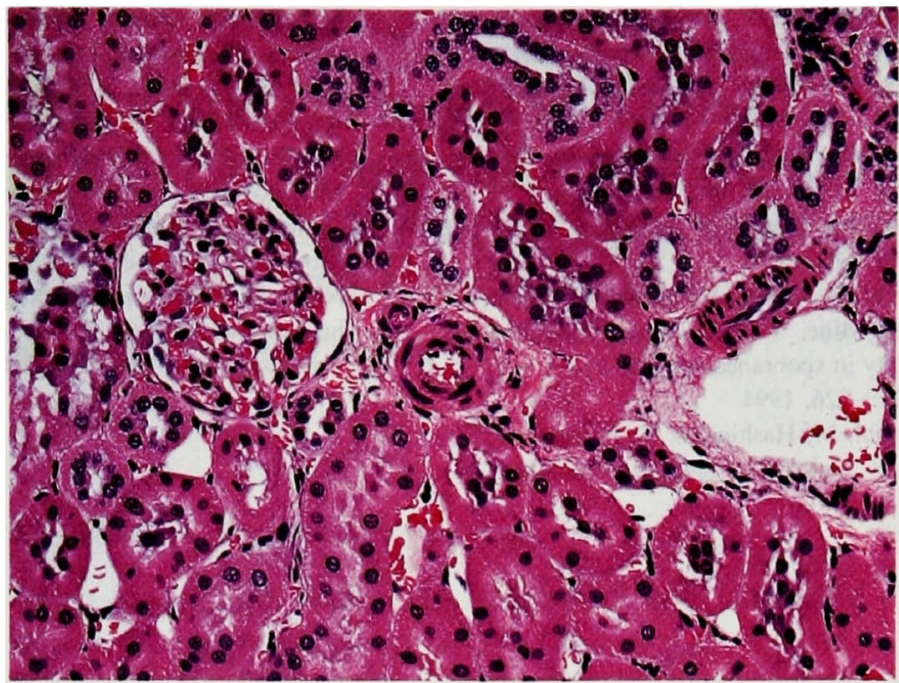

Fig. 10. No noteworthy changes in the kidney of FK506 $(4 \mathrm{mg} / \mathrm{kg} /$ day $)$ for 2 weeks. HE $\times 100$

II antagonist on the nephrotoxicity corresponded to the increase of urinary TX $\mathrm{B}_{2}$ and elevation of plasma renin activity, respectively. $\alpha_{2}$ blocker was used to examine the effects on sympathetic factors and exerted a slight improvement, suggesting that the sympathetic nerve system is partly involved in the constriction of the renal vessel. In consideration of the effects of endocelin and platelet activating activator (PAF) induced from the endothelia, these antagonists were also given to the animals, but they had no improving effects for the nephrotoxicity. The calcium channel blocker was the most effective of all antagonists. $\mathrm{Ca}^{2+}$ ions play an important role in the constriction of the muscle even when vasoactive factors are associated with the constriction. From this reason, $\mathrm{Ca}^{2+}$ channel blocker could be recommended as providing the best antidote to FK506-induced nephrotoxicity.

In the present study, some factors were considered to participate in the renovascular constriction by FK506. One of the most important things for concomitant dosing is that the blood levels of the main drug or associated agent do not change by concomitant dosing. FK506 is known to be metabolized by cytochrome $\mathrm{P}-450^{9}$ and dihydropyridine-derivative calcium-channel blocking agents are also metabolized by the enzyme system. Accordingly, there is a possibility that concomitant dosing with these agents would increase the blood levels of FK506. Nilvadipine, a dihydropyridine-derivative, was used as a $\mathrm{Ca}^{2+}$ channel blocker and the blood trough levels of FK506 were measured in the concomitant dosing with the drug. However, there were no changes in the blood levels of FK506 by any dosings of the calcium antagonist. This result suggests that each blood level does not change if each dosage is low. Additionally, concomitant $\mathrm{Ca}^{2+}$ channel blocker did not affect the immunosuppressive action of FK506, which is inhibition of antibody production (unpublished).

The present study was investigated for the effects of FK506 only on the kidney, one of the target organs. However, concomitant dosing may enhance the toxic potential of other organs. So, we should examine the toxic effects not only in the target organ, but in all organs as well.

\section{References}

1. Goto, T, Kino, T, Hatanaka, H, Nishiyama, M, Okuhara, M, Kohsaka, M, Aoki, H, and Imanaka, H : Discovery of FK-506, a novel immunosuppressant isolated from Streptomyces tsukubaensis. Transplant Proc 19 (Suppl. 6) : 4-8, 1987.

2. Starzl, TE, Todo, S, Fung, J, Demetris, AJ, Venkataramman, R, and Jain, A : FK506 for liver, kidney, and pancreas transplantation. Lancet 2: 1000-1004, 1989.

3. McDiarmid, SV, Colonna, JO, Shaked, A, Ament, ME, and Busuttil, RW : A comparison of renal function in cyclosporine- and FK-506-treated patients after primary orthotopic liver transplantation. Transplantation 56 : 847-853 1993.

4. Fung, JJ, Alessiani, M, Abu-Elmagd, K, Todo, S, 
Shapiro, R, Tzakis, A, Thiel, DV, Armitage, J, Jain, A, McCauley, J, Selby, R, and Starzl TE: Adverse effects associated with the use of FK506. Thansplant Proc 23 : 3105-3108, 1991.

5. Hebert, MF, Ascher, NL, Lake, JR, and Roberts, JP: Efficacy and toxicity of FK506 for the treatment of resistant rejection in liver transplant patients. Thansplant Proc 23 : 3109-3110, 1991.

6. Mitamura, T, Yamada, A, Ishida, H, Fujihira, S, Ohara, K, Noguchi, H, and Mine, Y: Tacrolimus (FK506)induced nephrotoxicity in spontaneous hypertensive rats. J Toxicol Sci 19 : 219-226, 1994.

7. Tamura, K, Kobayashi, M, Hashimoto, K, Kojima, K, Nagase, K, Iwasaki, K, Kaizu, T, Tanaka, H, and Niwa,
M : A highly sensitive method to assay FK-506 levels in plasma. Transplant Proc 19 (Suppl 6) : 23-29, 1987.

8. Kyo, M, Takahara, S, Kokado; Y, Ichikawa, Y, Ishibashi, M, Sonoda, T, Orita, Y, Onishi, S, and Kawaguchi, $\mathrm{N}$ : The effect of FK506 on renal functions in the rats : Morphological and biochemical study (in Japanese). Transplantation (Ishoku) 24 : 231-237, 1988.

9. Moochhala, SM, Lee, EJD, Earnest, L, Wong, JYY, and Ngoi, SS : Inhibition of drug metabolism in rat and human liver microsomes by FK506 and cyclosporine. Transplant Proc 23 : 2786-2788, 1991. 